REVISTAS DE LA FAHCE

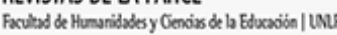

Educación Física y Ciencia

ISSN: 1514-0105

ISSN: 2314-2561

revistaefyc@fahce.unlp.edu.ar

Universidad Nacional de La Plata

Argentina

\title{
A valorização das produções culturais das crianças nas aulas de educação física: análises de narrativas docentes
}

Andreatta Scottá, Bianca; Lema Del Rio Martins, Rodrigo; Ventorim, Silvana; da Silva Mello, André

A valorização das produções culturais das crianças nas aulas de educação física: análises de narrativas docentes

Educación Física y Ciencia, vol. 22, núm. 1, 2020

Universidad Nacional de La Plata, Argentina

Disponible en: http://www.redalyc.org/articulo.oa?id=439963095012

DOI: https://doi.org/10.24215/23142561e120

Esta obra está bajo una Licencia Creative Commons Atribución-NoComercial-Compartirlgual 4.0 Internacional. 


\title{
A valorização das produções culturais das crianças nas aulas de educação física: análises de narrativas docentes
}

\author{
Bianca Andreatta Scottá \\ Universidade Federal do Espirito Santo - UFES, Vitórial \\ ES, Brasil. Grupo de pesquisa: Núcleo de Aprendizagens \\ com as Infâncias e seus Fazeres (NAIF), Brasil \\ bia.andreatta3@hotmail.com \\ Rodrigo Lema Del Rio Martins \\ Universidade Federal do Rural do Rio de Janeiro - UFRRJ, \\ Seropédica/RJ, Brasil. Grupo de pesquisa: Núcleo de \\ Aprendizagens com as Infâncias e seus Fazeres (NAIF), \\ Brasil \\ Silvana Ventorim \\ Universidade Federal do Espirito Santo - UFES, Vitórial \\ ES, Brasil. Grupo de pesquisa: Instituto de Pesquisa em \\ Educação e Educação Física (Proteoria), Brasil \\ André da Silva Mello \\ Universidade Federal do Espirito Santo - UFES, Vitórial \\ ES, Brasil. Grupo de pesquisa: Núcleo de Aprendizagens \\ com as Infâncias e seus Fazeres (NAIF), Brasil
}

The valorization of children's cultural productions in the physical education classes: teacher's narratives analysis

DOI: https://doi.org/10.24215/23142561e120

Redalyc: http://www.redalyc.org/articulo.oa?

\section{Resumo:}

Analisa como os professores de Educação Física têm dado visibilidade às produções culturais das crianças na Educação Infantil e de que forma essas produções potencializam as suas mediações pedagógicas nesse contexto. Utiliza a narrativa (auto)biográfica como método. Os dados foram produzidos por meio das narrativas de duas professoras e de dois professores de Educação Física que atuam em Centros Municipais de Educação Infantil (CMEI) de Vitória/ES/Brasil. As narrativas docentes foram potencializadas pelos “episódios de interação", que ilustram situações prototípicas em que as produções culturais das crianças foram reconhecidas e valorizadas nas mediações pedagógicas. Os resultados sinalizam diversas estratégias utilizadas pelos docentes para auscultarem e valorizarem as produções infantis, dentre elas, destacam-se: as relações dialógicas com as crianças; a reelaboração da intencionalidade pedagógica do professor, considerando as demandas das crianças; os arranjos de materiais; e a valorização da reprodução interpretativa que as crianças imprimem aos artefatos culturais que lhes são ofertados.

Palavras-chave: Mediações pedagógicas, Educação Física, Educação Infantil, Produções culturais.

\section{Abstract:}

It analyzes how Physical Education teachers have given visibility to children's cultural productions in Early Childhood Education and how these productions potentiate their pedagogical mediations in this context. Uses autobiographic narrative as method. The data were produced through the narratives of two female and two male Physical Education teachers who work in Municipal Children's Education Centers (CMEI) in Vitória/ES-Brazil. The teacher's narratives were strengthened by "interaction episodes", which illustrate prototypical situations in which children's cultural productions were recognized and valued in pedagogical mediations. The results indicate several strategies used by teachers to listen to and value children's productions, among which the following stand out: dialogical relationships with children; the re-elaboration of the pedagogical intentionality of the teacher, 
considering the demands of the children; the arrangement of materials; and the valorization of the interpretive reproduction that the children print to the cultural artifacts that are offered to them.

KeYworDs: Pedagogical mediations, Physical Education, Early Childhood Education, Cultural productions.

\section{INTRODUÇÃo}

A infância é uma categoria social, historicamente construída, formada por diferentes estatutos sociais, bases ideológicas, normativas e referenciais que oferecem suporte para a consolidação de representações e concepções sobre as crianças na sociedade (Sarmento, 2005). Ao longo da história, as concepções de infância se modificaram, migrando de um extremo, que concebia as crianças como seres imaturos e incapazes, para outro, que passa a considerá-las como seres sociais plenos, produtores de cultura, que transformam e são transformadas pelos contextos em que estão inseridas (Dahlberg, Pense \& Moss, 2003).

Consideramos como produções culturais das crianças, suas práticas, enunciações, imaginações, inventividades, manifestações corporais e criações, que, por meio de suas culturas de pares (Corsaro, 2009), reverberam incessantemente no cotidiano da Educação Infantil. Os infantis não recebem apenas uma cultura construída, mas operam transformando essa produção cultural, seja sob a forma de interpretar e integrar, seja nos efeitos que nela produzem por meio de suas próprias práticas (Sarmento, 2013).

Apesar da construção de novas concepções de infância, as anteriores não deixaram de existir, mas passaram a ocupar o mesmo espaço ao longo do tempo, caracterizando o cenário histórico atual, em que diferentes concepções estão presentes simultaneamente em nossa sociedade. Para Barbosa (2002), superar concepções tradicionais sobre a infância é "situá-la historicamente, desvendar sua cultura, suas particularidades e aprender a tomar como modelo de trabalho não mais o ensino escolar, mas a Educação Infantil e todas as suas possibilidades" (p. 85), tendo como premissa as práticas inventivas das crianças, suas experiências de movimento e as relações que elas estabelecem entre seus pares.

Para Bellotti (2019), as crianças assumem as manifestações da cultura corporal na qual estão inseridas e, constituem conhecimentos, vivências e experiências que lhes permitem ter autonomia para resolver problemas ligados ao seu desenvolvimento na vida cotidiana. Construir diferentes olhares para o grupo social infantil e as suas instituições de ensino, pressupõe discutir os direitos das crianças de produzirem conhecimentos, abrir portas para ampliar as concepções de infância que incluam, também, as ideias das próprias crianças.

Para Corsaro $(2005,2009)$, as crianças são produtoras de suas infâncias, sujeitos capazes de criar e modificar aspectos culturais diretamente ligados à reprodução interpretativa, ou seja, elas se apropriam de forma criativa do mundo adulto para atenderem aos interesses próprios de sua categoria geracional. Essa perspectiva se materializa nas Diretrizes Curriculares Nacionais para a Educação Infantil (Brasil, 2009), que considera as crianças como:

Sujeito histórico e de direitos que, nas interações, relações e práticas cotidianas que vivencia, constrói sua identidade pessoal e coletiva, brinca, imagina, fantasia, deseja, aprende, observa, experimenta, narra, questiona e constrói sentidos sobre a natureza e a sociedade, produzindo cultura (p. 12).

Para Mello, Santos, Klippel, Rosa \& Votre (2014), a Educação Física na Educação Infantil enfrenta “(...) um desafio de natureza teórico-metodológica, que está associado à instituição de uma práxis pedagógica que considere as especificidades das crianças de zero a cinco anos e as singularidades das instituições de ensino destinadas a elas" (p. 469). Portanto, entre os principais desafios para a afirmação da Educação Física na Educação Infantil, destacamos o relacionado ao "como fazer", ou seja, o modo como as crianças devem ser ouvidas, interpretadas e consideradas nos processos de ensino-aprendizagem empreendidos pela Educação Física na Educação Infantil. 
As práticas pedagógicas da Educação Física na Educação Infantil devem garantir às crianças experiências que promovam a ampliação das suas vivências de movimento corporal, bem como potencializem as diferentes linguagens, processos de construção da sua autonomia e de interação com os sujeitos que compõem o cotidiano da Educação Infantil (Richter \& Vaz, 2005). Para Tomás (2017):

Os direitos da criança necessitam ser (re)apropriados/as pelos/as profissionais de educação, na sua visão crítica, como um guia emancipatório das suas práticas pedagógicas. Longe de ser irrelevante, a forma como se perspectivam as crianças pequenas, a sua educação e os seus direitos é essencial na forma como se pensam as práticas pedagógicas, se identificam os problemas e se delineiam os caminhos para a sua transposição. Diferentes concepções significam diferentes posicionamentos ante o reconhecimento e valorização das crianças, das suas vozes e das suas ações. (p. 15).

Considerando os argumentos expostos, este artigo tem como objetivo analisar a maneira como alguns professores reconhecidos por suas práticas pedagógicas inovadoras na Educação Infantil compreendem, interpretam e analisam as produções culturais das crianças em suas aulas de Educação Física e, ainda, de que forma essas produções, ao serem valorizadas, reorientam as suas práticas docentes. Para isso, dialogamos com quatro professores que atuam na rede pública municipal de Educação Infantil de Vitória/ES/Brasil, que foram indicados pelos próprios pares, ao reconhecerem que eles desenvolvem trabalhos que valorizam as agências e as autorias das crianças.

\section{Percurso teórico-metodológico}

Utilizamos a pesquisa narrativa (auto)biográfica (Souza, 2006, 2008) para compreendermos o modo como quatro professores de Educação Física reconhecidos por suas práticas pedagógicas inovadoras buscam valorizar as produções culturais das crianças em suas aulas. Essa abordagem expõe formas particulares dos processos formativos, experiências, histórias, aprendizagens e trajetórias dos sujeitos, permitindo que os mesmos narrem e reflitam sobre fatos de sua vida. Segundo o autor, na pesquisa narrativa (auto)biográfica, os professores se reconhecem nas histórias que contam de si, estando as narrativas que fazem de si marcadas por uma dinâmica de formação e investigação dos percursos profissionais e pessoais. Esse processo potencializa a abertura para experiências silenciadas e a elaboração de novas propostas sobre a profissão docente, contribuindo para a visibilização das vozes, dos conhecimentos e das práticas dos sujeitos em interação no cotidiano educacional.

Sendo assim, a perspectiva (auto)biográfica, permite reconhecer a riqueza das trajetórias dos professores como processos singulares e coletivos de produção de sentidos sobre a docência e criação de processos identitários na profissão. Como resultados de interações sociais, as narrativas de professores dizem das opções que cada uma delas fez ao longo da vida. Definimos as narrativas como produção de linguagem dos professores, pois acreditamos que elas derivam da interação verbal cuja realidade fundamental é seu caráter dialógico, isto é, faz parte de um processo de comunicação marcado pelas experiências vividas e pelas novas experiências adquiridas na relação com outros sujeitos. Assim sendo, cada grupo social e cada indivíduo "(...) tem seu repertório de gêneros discursivos que funciona como um espelho que reflete e retrata a realidade" (Jobim e Souza \& Castro, 2008, p. 62).

Entendemos que as narrativas dos sujeitos se fazem com base em suas histórias de vida, construídas nas relações sociais, mediadas pela cultura e pela linguagem, possibilitando a produção de subjetividades na construção de múltiplos sentidos sobre os próprios processos de formação e de trabalho docente. Portanto, as narrativas das experiências são sempre inéditas e carregadas de sentidos, produzidos na confluência das histórias de quem narra e de quem escuta, numa relação intersubjetiva.

No primeiro contato com os professores (duas mulheres e dois homens), nos horários de planejamentos de suas aulas, apresentamos a proposta de investigação e solicitamos o consentimento de participação no estudo.

${ }^{1}$ No processo de construção das narrativas (auto)biográficas solicitamos que os professores apresentassem 
alguns episódios de interação. Denominamos de "episódio de interação", uma sequência interativa, que se pode relembrar e relatar por meio de atividades pedagógicas que são mediadas pelos adultos e praticadas por uma ou mais crianças (Pedrosa \& Carvalho, 2005).

Esses episódios são prototípicos do fenômeno estudado, pois apresentam características significas daquilo que se busca evidenciar. Os "episódios de interação" foram selecionados com a nossa participação, narrados de forma livre por cada um dos professores, registrados em áudio e transcritos em diário de campo. As fotografias impressas e digitais foram utilizadas como fontes de produção de dados igualmente significativas para o processo de narração pelos sujeitos na mediação dialógica com os pesquisadores.

Assim, a pesquisa esteve marcada pela partilha de experiências entre as professoras e os pesquisadores, de modo que a situamos no "modelo interativo ou dialógico" (Souza, 2006), pois adotou "uma nova relação de lugar entre o pesquisador e os atores sociais, tendo em vista uma co-construção de sentido”. (p. 27). A análise dos dados provenientes dessas fontes está articulada com a literatura mobilizada neste artigo, em especial, com os pressupostos da Sociologia da Infância.

\section{Resultados e Discussão}

\subsection{Episódio de Interação 1}

O episódio narrado pela professora Gal, é derivado da reportagem retirada do website da Prefeitura Municipal de Vitória/ES (PMV), intitulada: "Cmei de Jardim Camburi recebe brinquedoteca feita pelos próprios alunos", como mostra a Imagem 1:

\section{IMAGEM 1}

Recorte do Website da PMV sobre a construção da brinquedoteca

\section{Cmei de Jardim Camburi recebe brinquedoteca feita pelos próprios alunos}

Publicada em 12/12/2016, as $19 h 26$

\begin{tabular}{|c|c|c|c|c|}
\hline & $f$ Partilhar 0 & Gosto 0 & G+1 \\
\hline
\end{tabular}
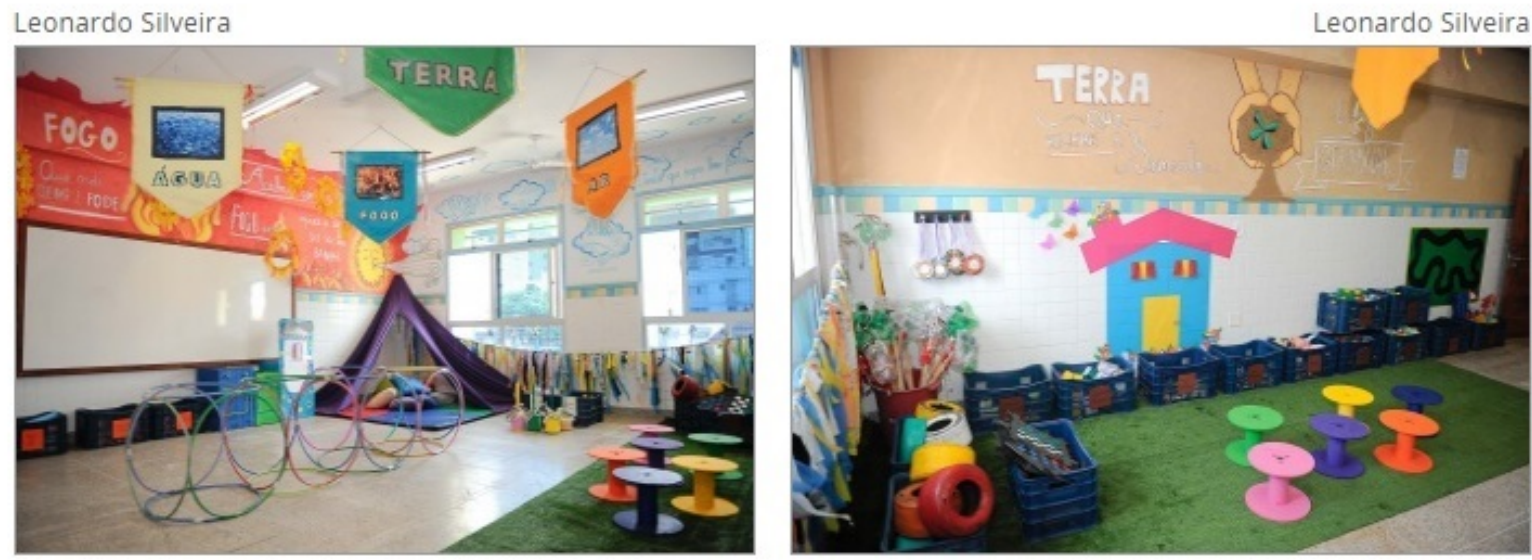

Website da Prefeitura Municipal de Vitória/ES 
O projeto de revitalização da brinquedoteca foi desenvolvido por professoras de Educação Física em parceria com estudantes de Educação Física, bolsistas do Programa Institucional de Bolsa de Iniciação à Docência (Pibid/EF/Ufes), ${ }^{2}$ e com as crianças do Cmei. A estrutura e demais complementos que compõem a brinquedoteca foram montados a partir de um diálogo estabelecido com as crianças nas aulas de Educação Física. Esse espaço, atualmente, é composto principalmente por brinquedos não estruturados produzidos pelos infantis no decorrer de um trabalho pedagógico pautado na sustentabilidade. As paredes, o chão e todos os demais objetos foram concebidos para promover a aventura do novo, o reconhecimento e a apropriação de diferentes espaços. Segundo Santos, Silva, Melo, Santos \& Fonseca (2011), a educação para sustentabilidade ainda é um tema muito recente e pouco discutido na Educação Infantil, principalmente pela facilidade que algumas dessas Instituiçóes têm de disponibilizar brinquedos já estruturados para as crianças.

A importância da reutilização ecológica é um tema que deve ser trabalhado com crianças de todas as idades e uma boa maneira é produzindo brinquedos próprios e originais, valorizando o ato de reutilizar materiais de difícil deterioração e que são comumente descartados pelos seres humanos em locais impróprios. Ao lermos a matéria publicada pela prefeitura de Vitória/ES/Brasil, ficamos instigados a compreender a maneira como a professora deu voz, dialogou e interpretou as manifestações das crianças na reconstrução da brinquedoteca.

A professora Gal inicia sua narrativa falando da percepção que as professoras de Educação Física tiveram das aulas que estavam sendo desenvolvidas por meio do eixo da Cultura Popular. Nessas atividades, perceberam que as crianças interagiam pouco com seus pares e com os elementos que lhes eram dados, ou seja, brincavam por si só, ocorriam poucas interações nas aulas, como mostra o relato:

Nós precisávamos trazer elementos que convidassem as crianças a interagir mais com seus colegas. Foi aí que começamos a pensar propostas para que isso se efetivasse, por exemplo: materiais, cenários, que tipo de materiais nós poderíamos utilizar para aguçar tais sentidos nelas, como a criatividade, interação, imaginação e criação. Em busca de subsídios para aguçar tais sentidos nelas, começamos a pesquisar, e chagamos ao documentário “Território do Brincar”, que mostrava diferentes modos da criança interagir com matérias ecológicos (Narrativa da Professora Gal, produzida em 10-7-2017).

Essa percepção desencadeou muitos questionamentos que fizeram com que a professora buscasse por um "ambiente potencializador", que aguçasse sentidos e significados nas crianças, que apresentasse novas possibilidades de expressão e de interações. Segundo Cunha (2010), a brinquedoteca é um desses espaços promotores de criações, que estimula a criança a brincar com uma grande variedade de elementos num espaço totalmente lúdico e convidativo, explorando, sentindo e experimentando as possibilidades que o ambiente oferece. Foi a partir desse entendimento que as professoras de Educação Física começaram a olhar para a brinquedoteca do Cmei, que naquele momento permanecia fechada e inutilizada, pelo mau uso dos brinquedos e objetos que a compunham, como mostra a narrativa da professora:

Então resolvemos chamar as crianças e levar até aquele espaço e perguntar: o que era aquele lugar, o que aquele lugar tinha, e o que ele precisava. Chegamos com as crianças na brinquedoteca e deixamos elas brincarem do jeito que esse espaço estava, com pouco brinquedo, sem brinquedos para todos, os poucos que tinham estavam estragados, mas deixamos elas brincarem livremente (Narrativa da Professora Gal, produzida em 10-7-2017).

A primeira estratégia utilizada para pensar no processo de reconstrução deste espaço foi levar as crianças até ele e perguntar-lhes o que aquele lugar tinha, como estavam todos os materiais, e ainda, o que ele precisava para se tornar um ambiente de alegria, afeto, magia, produção e expressividade. A captação das linguagens, impressões e significações das crianças diante daquele espaço, que no momento era composto por brinquedos quebrados, mal posicionados, desorganizados e sem quantidades para todos, facilitou pensar numa estratégia de revitalização. Concordamos com Varotto \& Silva (2004), que as crianças, muitas vezes, quebram os brinquedos prontos (bonecas, carrinhos, bambolês, quebra-cabeças), não querendo, dialeticamente, destruir, mas é um destruir para construir e reconstruir, imprimindo suas marcas. Por esse espaço não apresentar nenhuma intencionalidade pedagógica da maneira como estava, as crianças necessitavam reconstruí-lo a todo o momento, dando novos sentidos a ele. 
Com essa estratégia de dar voz às crianças e tentar compreender os desejos que elas estavam manifestando sobre aquele espaço, professoras e bolsistas do Pibid tiveram que pensar na materialização de um projeto que potencializasse os processos de apropriação e produção dos infantis. De acordo com Mello et al. (2015), dar visibilidade às produções infantis e às maneiras específicas pelas quais se apropriam e se constituem como autoras de suas próprias vidas, contribui para a constituição de novas pedagogias que reconheçam e valorizem os interesses, necessidades e expectativas das crianças. Nessa direção, os sujeitos começaram a realizar atividades e produzir brinquedos com as crianças para comporem a brinquedoteca. $\mathrm{O}$ projeto desenvolvido englobava os diferentes elementos da natureza (ar, terra, fogo e água), como eixos temáticos do trabalho pedagógico. Esses elementos foram divididos para que cada temática fosse trabalhada a cada dois meses, sendo que tudo que as crianças produziam, criavam e sinalizavam era armazenado para compor a nova brinquedoteca.

A parte estética da brinquedoteca que necessitava da mão adulta, como: pinturas das paredes, manuseio de materiais que eram impróprios para a faixa etária das crianças - cola quente, agulha, cola de piso, tesoura, estilete e etc., ficara a cargo de um artista plástico, dos alunos do Pibid e das professoras que exerciam docência no Cmei. Foram 10 meses trabalhando e produzindo elementos junto com as crianças. A composição, produção e revitalização da brinquedoteca aconteceram de modo gradativo, sendo produzida aos poucos junto com as crianças, que quando entram neste espaço se sentem pertencentes e criadoras, pois são suas produções. - "Tudo tem as mãos das crianças, em todos os cantos, entendo que a relação delas com o meio, com os materiais e com os outros, começou a ser diferente e significativa” Narrativa da Professora Gal, produzida em 10-7-2017).

Ao final da narrativa, perguntamos à professora qual foi o pressuposto que ela considerou fundamental para estabelecer essa troca cultural com as crianças, dando-lhes a autonomia de serem as principais produtoras e reconstrutoras daquele espaço. Ela aponta como principal estratégia a relação dialógica estabelecida com as crianças, como mostra a narrativa a seguir:

O Diálogo estabelecido com as crianças durante todo o processo. Eu priorizo muito nas minhas aulas as falas das crianças e suas interações, pois sem esses pressupostos não há como atribuirmos protagonismo a elas, não há como reconhecermos elas como produtoras de cultura. Podemos simplesmente dizer que elas são produtoras, mas não estamos dispostos a dialogar, não fazemos uma leitura do que elas estão manifestando, elas se manifestam, elas choram, elas riem e se expressam por diferentes linguagens. O professor tem que estar disposto a fazer essa leitura (Narrativa da Professora Gal, produzida em 10-7-2017, grifo nosso).

Rezende (2012) corrobora com a problematização do diálogo e das trocas culturais que acontecem entre os sujeitos que compóem o ambiente escolar, mostrando que mesmo as crianças tendo abertura nas aulas para seguirem a lógica de seus desejos e vontades sem a interferência do adulto, necessitam das trocas culturais para se tornarem sujeitos atuantes em seu contexto social. Concordamos com Gómez-Smyth \& Capllonch-Bujosa (2015) que o professor que se coloca em uma posição de escuta sensível frente às linguagens manifestadas pelas crianças, se destaca como um parceiro que potencializa a interação entre os pares, exercendo um papel democrático, não autoritário, na medida em que possibilita às crianças expressem seus desejos e interesses por meio dos jogos e brincadeiras nas aulas.

\subsection{Episódio de Interação 2}

O episódio de interação escolhido junto com o Professor Chico, focaliza as marcas que as crianças imprimiram na atividade proposta que, em um primeiro momento, estava organizada para ocorrer de uma maneira, mas elas foram adaptando o espaço e os materiais às suas necessidades e expectativas.

O Professor Chico tentou construir um brinquedo típico de parques e áreas de recreação infantil, popularmente chamado, no Brasil, de trepa-trepa. Esse equipamento de lazer consiste em diversas traves de metal, dispostas horizontal e verticalmente, permitindo escaladas e travessias. Escolhemos o episódio decorrente da brincadeira realizada nesse brinquedo, pois o referido professor o identificou como um momento de muito aprendizado, que contribuiu com a sua percepção sobre o modo como as crianças se apropriam dos bens culturais que lhes são ofertados. 
Segundo o Professor Chico, a ideia de proporcionar essa brincadeira para as crianças surgiu quando estava trabalhando a cultura circense com elas. Um dos eixos desse trabalho era promover "atividades suspensas", explorando ações como: subir, pendurar, balançar e equilibrar. Como o seu CMEI não dispunha de um trepa-trepa, a alternativa encontrada foi a de adaptar uma grade metálica, em formato de escada, que havia encontrado descartada pela igreja da comunidade a que pertence. Para que essa grade ficasse suspensa no pátio do CMEI, e as crianças não tivessem contato com o chão, o professor se baseou na altura da criança de maior estatura no Grupo 6 (crianças com aproximadamente cinco anos de idade) e amarrou a grade nas quatro pilastras do pátio, com cordas de um diâmetro que suportasse o peso delas. A pretensão inicial do professor, ao pensar nessa forma de brincar com trepa-trepa construído, era que as crianças realizassem a travessia na grade de um lado para o outro, se pendurando, como evidencia a narrativa:

Eu estava com aquele material ali e a ideia seria 'a Brincadeira', o brincar de subir e de explorar a travessia, porque se você olha a grade, ela dá uma progressão da pegada, então eu pego uma haste, largo, pego a outra, e assim sucessivamente. Eu dava um direcionamento inicial, pedindo para eles imitarem um morcego, e deixava que elas criassem livremente suas imitaçôes e formas de se pendurar. Eu sempre falava 'olha que legal como fulano fez, vamos fazer igual a ele?' (Narrativa do Professor Chico, produzida em 1-8-2017).

Com a altura da grade direcionada para o Grupo 6, as crianças do Grupo 5 (crianças com aproximadamente quatro anos de idade) tinham dificuldade de agarrar e se pendurar na grade por causa das suas estaturas, necessitando constantemente do auxílio do professor. Nesse processo de auxiliá-las a agarrarem a grade, uma delas, sem que o docente percebesse, buscou outra alternativa, utilizando elementos disponíveis no espaço em que a aula estava ocorrendo, como mostram a Imagem 2 e a narrativa de Chico, a seguir:

\section{IMAGEM 2}

Crianças utilizando o pneu para alcançarem a grade

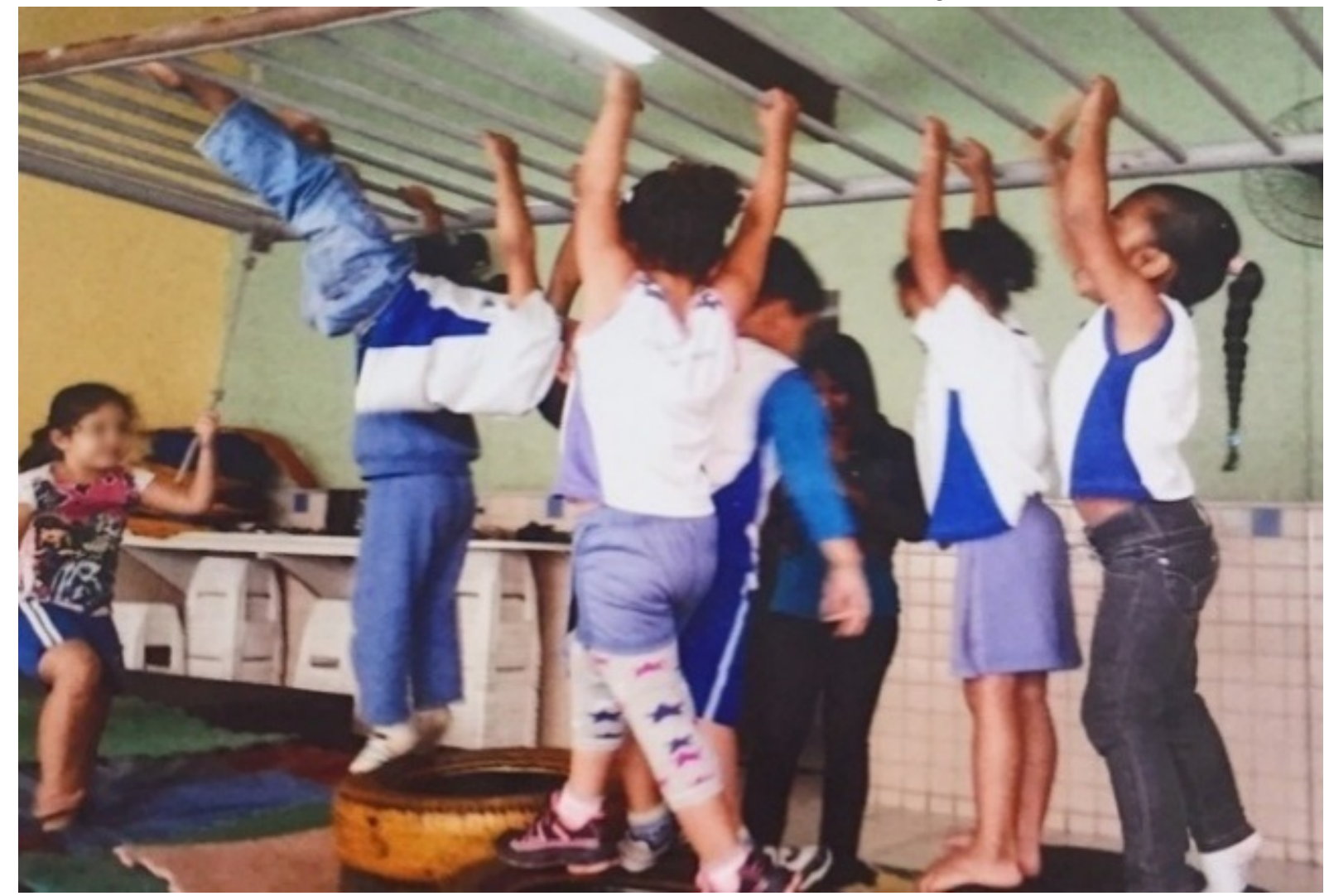

Acervo professor Chico 
Uma criança, sem que eu percebesse, pegou um pneu, puxou, colocou em baixo da grade e agarrou com as mãos. Esses pneus ficam no cantinho do pátio, eu vi aquilo e deixei, aí juntou todo mundo no mesmo pneu. Fui pegando os outros e jogando aleatoriamente em cima do colchão e elas começaram a usar essa estratégia a partir da manifestação dessa criança. Mas aí, outra criança um pouco menor percebeu que um pneu ainda não era suficiente e colocou um em cima do outro alcançando a grade, ou seja, ela criou outra forma de alcançar, ela usou a experiência do outro para ter autonomia no seu movimento. Eu sempre as deixo demonstrarem suas vontades a partir da brincadeira, acredito que o professor não deve privar a criança de utilizar todos os espaços e implementos presente no seu meio, para deixar a brincadeira mais atrativa e interessante (Narrativa do Professor Chico, produzida em 8-8-2017).

A narrativa do professor Chico explica a Imagem 2, em que as crianças buscaram diferentes alternativas daquelas orientadas por ele para a utilização do trepa-trepa construído. Por esse ângulo, Martins, Santos, Mello \& Votre (2016), baseados nas contribuições teóricas de Certeau (1994), sinalizam que as crianças agem taticamente ${ }^{3}$, a margem do planejamento formal das aulas, experimentando alternativas para fazer valer a suas vontades. Asseguram ainda que,

São nos momentos fugidios do olhar adulto que elas aproveitam para estabelecer relações instituintes de negociação, jogo de papéis e regras acerca das formas de brincar e de operar com os objetos, espaços-tempos e com as atividades que mais lhes interessam (Martins et al., 2016, p. 64).

Esse processo de reformulação só se efetivou, porque o Professor Chico estabeleceu uma postura sensível as manifestações e as criações das crianças. Ao invés de reprimir, corrigindo o que faziam por terem modificado o modo de execução planejado, deixou que as crianças utilizassem os pneus. Assim sendo, favoreceu que elas criassem novas formas de brincar com aquele objeto e, com isso, além de encontrarem alternativas para brincar com o trepa-trepa construído, também começaram a dar sentidos diferentes ao realizar movimentos diversos para esse equipamento. Essa postura do professor em reconhecer o potencial criativo e autoral das crianças, é destacado positivamente por Neira (2008), pois, para ele, o exercício de um olhar sensível paras as produções culturais infantis permite aos adultos conhecerem os interesses das crianças e os conhecimentos que estão sendo apropriados por elas nas mediações pedagógicas promovidas nas aulas.

As experiências corporais compartilhadas pelas crianças davam novos encaminhamentos e, a partir disso, o professor Chico foi construindo sua aula com os fazeres manifestados por elas, "todo movimento que elas manifestavam, era uma experiência singular e autônoma de criação, o desequilíbrio, o equilíbrio, a queda, o salto e o subir, tudo num conjunto, naquela estrutura" (Narrativa do Professor Chico, produzida em 8-8-2017).

Para que as crianças tenham a possibilidade de ressignificar um conhecimento mediado pela prática pedagógica do professor, é necessário que ele esteja disposto a atuar como facilitador do conhecimento, no sentido de preparar e fornecer espaços, materiais, sugestões e auxílio, para que elas sejam protagonistas de suas ações (Dupuy, 2019). Consideramos relevante que o professor estimule as crianças em suas aulas a agirem e solucionarem problemas e questionamentos por si mesmos, com base na sua condição de poder fazer e em suas experiências.

Nessa perspectiva não diretiva de abordar as brincadeiras, as crianças ganham autonomia para organizarem e decidirem sobre os procedimentos que irão utilizar para fazerem valer suas vontades. Uma alternativa é estimular o processo de apropriação e produção das crianças dispondo no espaço "arranjos de aparelhos", isto é, materiais estruturados e não estruturados que estimulem seus processos criativos. Segundo Horn (2004), oportunizar o manuseio de um material que aguce a criatividade dos infantis permite que eles criem e recriem sua realidade, produzindo cultura.

A criatividade das crianças está relacionada à produção e à manifestação de algo novo, presente no seu universo simbólico e nas relações que elas estabelecem com os elementos presentes em seus contextos. Segundo Sarmento (2005), as crianças apresentam modos diferenciados de interpretação, reprodução e simbolização do real, que se constroem nas culturas da infância por meio dos jogos e das brincadeiras. Elas não imitam ou copiam o mundo dos adultos, mas transformam, modificam e contestam, pensam e elaboram ideias 
próprias. Portanto, nos posicionamos a favor do brincar espontâneo e autônomo como um direito inalienável da infância, permitindo que as crianças experimentem, testem, explorem e descubram suas preferências, sempre em interação com os outros e com o meio em que estão inseridas, dando novos significados a sua cultura corporal infantil (Gómez-Smyth, 2017, 2019).

\subsection{Episódio de Interação 3}

$\mathrm{Na}$ interlocução com a professora Mercedes, buscamos examinar um episódio de interação que contribuísse significativamente para compreendermos os pressupostos utilizados pela referida docente para considerar as produções culturais das crianças em suas aulas de Educação Física. Ela narra que em sua prática pedagógica busca sempre trabalhar com "temas emergentes". Um dos temas trabalhados que marcou muito o seu processo formativo com os infantis foi no ano dos Jogos Olímpicos do Rio de Janeiro, em 2016, em que crianças não tinham contato com esse tipo de competição e, nem mesmo, com as práticas que são disputadas. Nesse sentido, definimos que o episódio partiria desse tema "Olimpíadas", que foi significativo não só para a professora, mas, também, para as crianças.

Muitos pesquisadores da área consideram o esporte inapropriado para a Educação Infantil, principalmente por suas características competitivas e padronizadas do movimento. Contudo, concordamos com Bellotti (2019), de que, mesmo o esporte recebendo essa conotação pejorativa, as crianças têm o direito de conhecer, experimentar e ressignificar esse fenômeno sociocultural por meio de brincadeiras com o esporte. Com efeito, o trabalho pedagógico tematizando o esporte, orientado por um viés mais crítico, pode representar uma valiosa oportunidade de inovar na abordagem dessa manifestação da cultura corporal na Educação Infantil.

Inicialmente, quando a professora pensou em trabalhar pedagogicamente as Olimpíadas, ela não havia identificado como estava o repertório motor daquelas crianças, o que elas sabiam sobre as Olimpíadas e o que entendiam por esporte. A estratégia inicial da docente foi criar um quadro no pátio da escola. Nele, seriam expostas as ideias das crianças em relação ao esporte, com a pergunta: "O que é esporte para você?". Essa questão gerou uma grande árvore de opinióes, como mostra a narrativa a seguir:

Uns falavam “esporte é correr, esporte é brincar, é jogo de futebol, é queimada, é pega-pega”. Já no Grupo 3, pensei: “como vou abordá-los?” Eles são tão pequenos, não vão me dizer nada. Mas aí, as crianças falaram: “Tia, esporte é Lazy Town”. Logo pensei: “o que seria isso?”, “Como vou colocar na árvore de palavras?”. Eu não tinha noção do que era e na tradução percebi que significava "A Cidade da Preguiça”. Minha reação? Fiquei chocada. Busquei saber mais e era um desenho é um musical educativo infantil. Nele, os personagens tentam tirar as crianças da preguiça, fazendo muitos exercícios, piruetas e saltos. Ou seja, as crianças tinham entendido. Aquilo tinha um significado do que era esporte para elas. E foi a partir dessa estratégia que fomos trabalhando o esporte, a partir de cada fala e manifestação delas (Narrativa da professora Mercedes, produzida em 12-8-2018).

Foi com essa estratégia que iniciaram as atividades que envolviam as Olimpíadas com as crianças, apresentando algo e, a partir do que elas traziam como devolutiva, a professora Mercedes problematizava, buscando maneiras de dar visibilidade a essas manifestações culturais, tornando as crianças autoras de todo processo. Desde o momento inicial, as crianças tinham autonomia sobre as atividades que estavam sendo desenvolvidas. Com efeito, criaram a árvore de palavras, os símbolos Olímpicos, as suas próprias medalhas de cores e formatos diferentes, bem como produziram as bandeiras dos países que participariam das Olimpíadas, aprendendo sobre a cultura, as tradições e as brincadeiras desses países. Nas corridas de revezamento, ao invés de serem corredores, tornavam-se super-heróis corredores, com capas e máscaras feitas pelas próprias crianças. Todas essas atividades que foram trabalhadas com as crianças partiram delas e das suas enunciações verbais. Mercedes narra que, quando já estavam finalizando as atividades sobre as Olimpíadas, um aluno do Grupo 6 chega até ela e à questiona:

Mas, professora, não vamos ter uma mascote? As Olimpíadas têm mascotes (Narrativa da Professora Mercedes, produzida em 12-8-2017). 
Eu nem havia pensado nisso. Então, começamos a perguntar qual mascote as crianças queriam para representá-las. Algumas diziam os originais criados para as Olimpíadas, outras diziam, uma coelha mascote, uma ursa mascote, gavião mascote, bonecas, carrinhos e etc., foram muitas ideias. Então, decidimos que cada turma produziria uma mascote que a representasse e nós faríamos um concurso para escolhermos o que representaria a escola. (Narrativa da Professora Mercedes, produzida em 12-8-2017).

Depois de muitas ideias, desenhos, imaginações, fantasias, invenções e criações das crianças, os votos foram contabilizados e a mascote escolhida. Tudo partiu das crianças, desde a composição corporal na qual as mascotes tomavam forma, passando pelas cores até os próprios nomes. A Imagem 3, a seguir, mostra a mascote escolhida, desenhada e nominada pelas crianças:

IMAGEM 3

Mascote criado pelas crianças

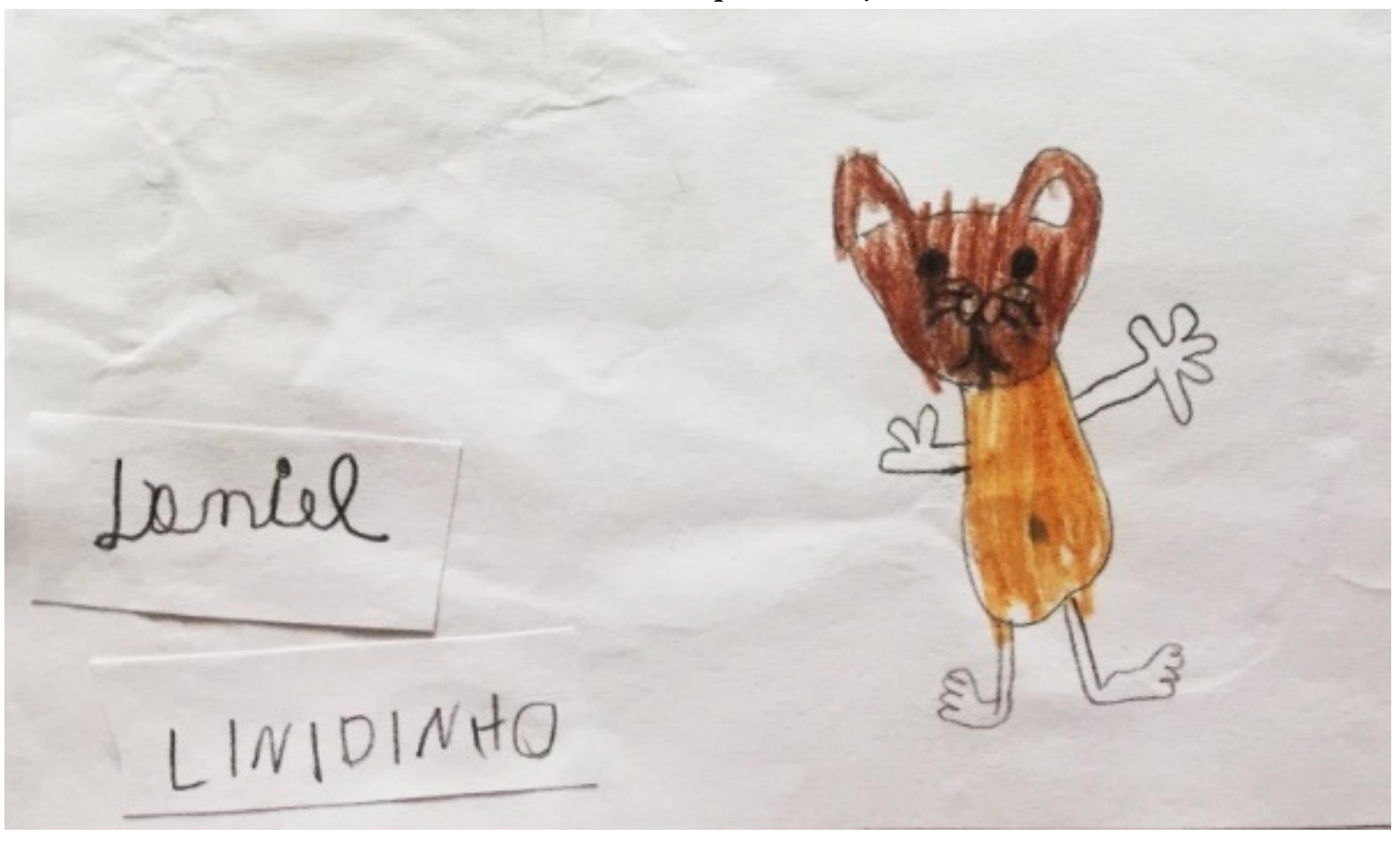

Acervo da professora Mercedes

A criação e a confecção da mascote se tornou um momento ímpar na formação dessas crianças, despertando nelas a vontade de serem cada vez mais participativas, produtoras e ativas nas dinâmicas que envolvem o contexto escolar. Cada criança carrega consigo, valores, experiências, saberes, desejos, subjetividades, linguagens e práticas, porém cabe ao professor criar possibilidades e situações para que elas se sintam autoras e que manifestem suas produções. De acordo com Pinto e Sarmento (1997), a consideração e valorização das crianças como atores sociais ocorre pelo modo específico como apresentam características próprias, fantasiam o mundo, as brincadeiras e produzem cultura na relação com seus pares e adultos. Sendo assim, "as crianças precisam ser vistas como coconstrutoras de conhecimento e cultura, e essa visão implica reconhecer suas expressões nas mais variadas linguagens" (Portilho \& Tosatto, 2014, p. 742).

Nesse sentido, o que significa valorizar as produções culturais das crianças? Valorização é o aumento do valor, da importância, isto é, um mérito atribuído a um ato, coisa ou pessoa, de acordo com um olhar subjetivo do outro (Borba, 2002). As instituições de Educação Infantil e os professores devem “(...) assegurar às crianças a manifestação de seus interesses, desejos e curiosidades ao participar das práticas educativas, valorizar suas produções, individuais e coletivas, e trabalhar pela conquista por elas da autonomia" (Brasil, 2013, p. 87). Valorizar as produções culturais das crianças está muito além de apenas dar-lhes o protagonismo, 
deixando que brinquem sozinhas. É preciso criar possibilidades, contextos, situações e histórias que deixem suas imaginações fluírem, que sejam autoras e produtoras ativas na construção dos seus processos sociais, individuais e autônomos.

Em sentido complementar, Gómez-Smyth (2017) ressalta que, oportunizar às crianças exercitarem a sua autonomia criativa, não opõem liberdade e diretividade. Ao contrário, trata-se de uma mediação em que liberdade e diretividade se colocam de maneira complementar uma a outra no trabalho docente, afastando o caráter autoritário da relação professor-criança. $\mathrm{O}$ autor defende que haja uma constante e atenta observação das criações, dos interesses e dos desinteresses manifestados pelas crianças em situação de aulas de Educação Física, visando promover a autonomia individual e coletiva dos sujeitos que frequentam a Educação Infantil.

\subsection{Episódio de Interação 4}

O episódio narrado pelo professor Caetano é decorrente de um projeto intitulado: "Brincadeiras Pintadas". A intenção desse projeto era proporcionar brincadeiras antigas que foram criadas e produzidas por crianças, como amarelinha, bolinha de gude, bolinha de sabão, pião, passa anel, pipa, cantigas de roda e etc. Para isso, utilizou pinturas de alguns artistas plásticos que retratam em suas obras crianças brincando. Os artistas utilizados foram Ivan Cruz, Candido Portinari, Peter Pregam e Ricardo Ferrari.

Entre eles, o que chamou mais a atenção das crianças foi Ivan Cruz, pela quantidade de quadros já produzidos, as cores vibrantes das obras e os traços simples e compreensíveis. Este artista já pitou cerca de 600 quadros, retratando mais de 100 brincadeiras na série "Brincadeiras de Criança", que passou a reunir exposições não só de quadros, mas de brinquedos confeccionados, oficinas de brincadeiras e contadores de histórias. O episódio escolhido é proveniente de um dos quadros de Ivan Cruz que retrata duas crianças brincando de fazer bolhas de sabão com canudos num vilarejo, pelo fato de ter sido a obra que mais chamou a atenção das crianças do CMEI que Caetano leciona.

\section{IMAGEM 4}

Tela "Bolha de Sabão", de Ivan Cruz (2007)

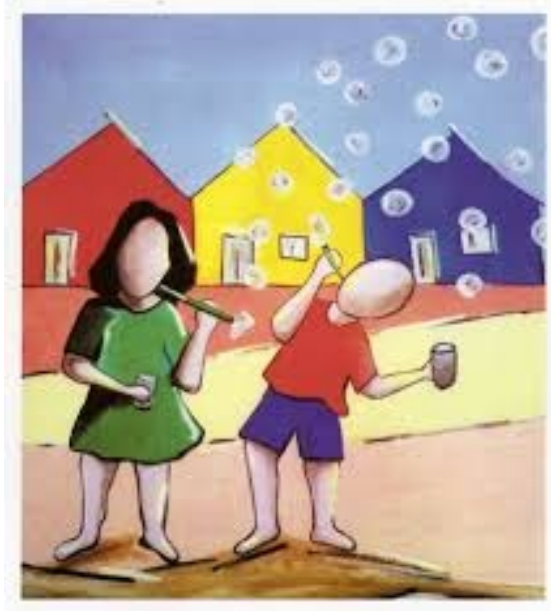

Galeria digital do artista Ivan Cruz ${ }^{4}$

Para iniciar essa brincadeira com as crianças, o professor Caetano apresentou com mais detalhes o quadro do artista plástico, com a intenção de problematizar e apontar as possibilidades de brincar que essa prática proporciona. A intenção do referido docente era adequar a brincadeira de bolhas de sabão à realidade das crianças e deixar que elas se apropriassem e brincassem com seus pares. Nesse processo, ele foi observando o modo como as crianças lidavam com a brincadeira e com os materiais disponibilizados. Ao passo em que 
manifestavam seus desejos, ele interpretava e dava um novo direcionamento, como: "vamos pular e soltar uma bolha?"; "Vamos soltar várias bolhas no ar?"; "Vamos fazer bolhas no chão?”. E, assim, as crianças iam reagindo aos estímulos do professor e realizando a brincadeira da maneira como interpretavam e conseguiam. As bolhas no chão foram novidade para as crianças, como mostra a narrativa abaixo:

Eu sempre brinquei de bolhas de sabão no chão quando era novo, mas nem imaginava que as crianças nunca tinham brincado. Separei elas em grupos no chão do pátio que tem uma plataforma lisa, expliquei que tinham que molhar o chão para as bolhas se fixarem. Entreguei copos com água e um pouco de sabão, ensinando-as como fazia, até porque não é tão simples como parece. Elas tinham que aprender a coordenarem o sopro, pois se soprassem muito forte a bolha poderia estourar. Uma coisa é no ar, que você solta e o vento leva, mas no chão é mais complexo. Devagar as crianças foram conseguindo e se ajudando, até que uma criança fez uma figura, dizendo que era um cacho de uva e eu pensei: “- Que legal!”. Aí, eu comecei a perceber que dava para fazer figuras também, e comecei a incentivá-los a criarem. (Narrativa do Professor Caetano, produzida em 16-8-2017).

A Imagem 5, a seguir, ratifica a narrativa do professor Caetano, em que a criança participa da brincadeira demonstrada por ele, imprimindo suas marcas e experiências, criando um cacho de uva com a junção de várias bolhas. 


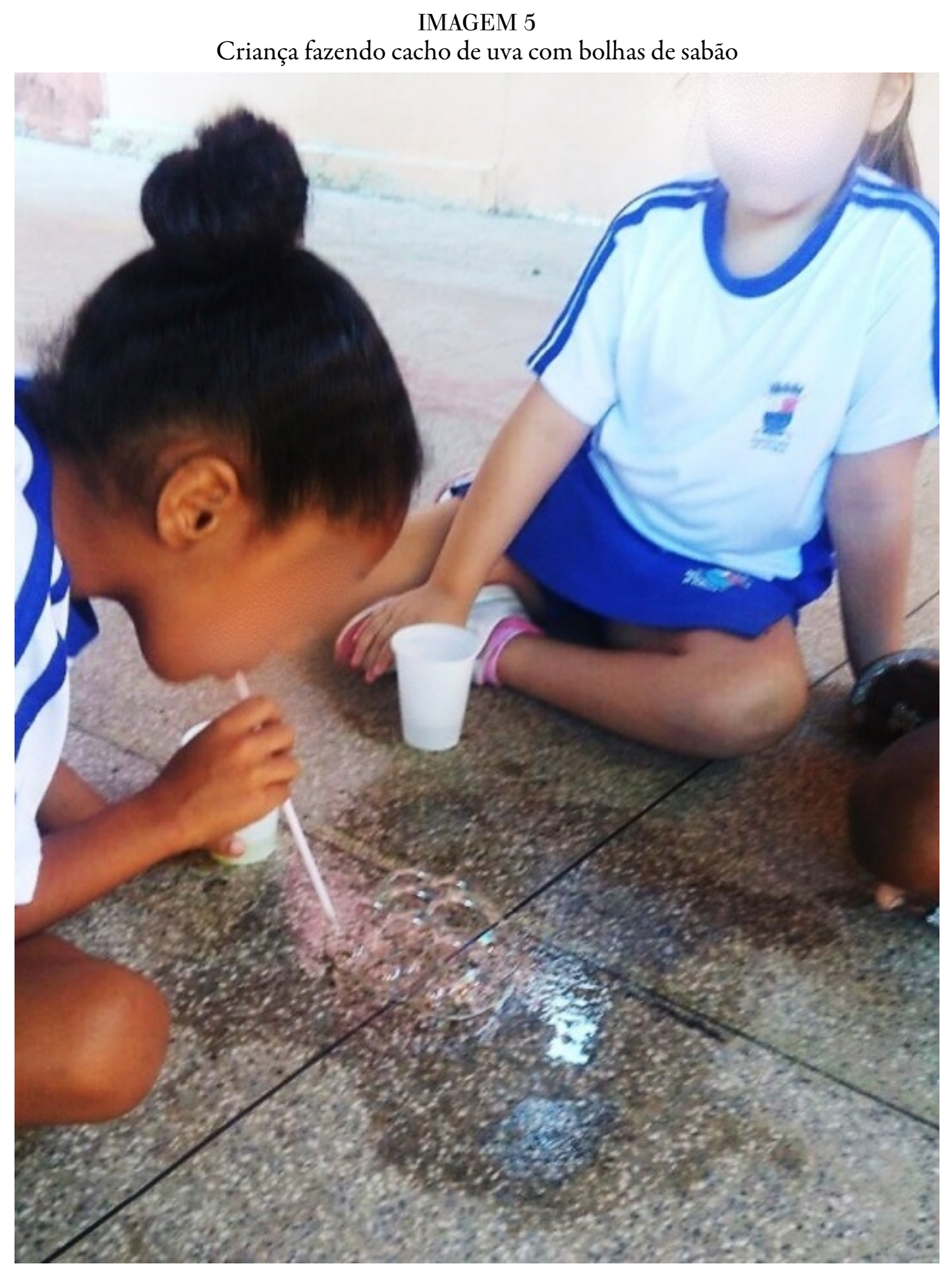

Acervo do professor Caetano

A partir disso, outras figuras foram sendo criadas pelas crianças, como: frutas, brinquedos, personagens como o Mickey, uma bola dentro da outra etc. Tudo que as crianças criavam dava novos direcionamentos para o professor Caetano que, ao ter essa percepção, já intencionava essas ações para as outras turmas. O modo peculiar e a produção dessa criança despertaram no referido docente a compreensão da ressignificação, criação e invenção que elas carregam em si, pois inicialmente ele nem imaginava que a brincadeira chegaria ao ponto de formar imagens com bolhas. As crianças nutrem-se das misturas e interfaces presentes nas relações que 
elas estabelecem com os outros em uma relação dialógica entre emissor e receptor, entre signos e significados (Ferrara, 2003) que, aos poucos, vão construindo suas identidades e culturas.

Corsaro (2005) nos apresenta o conceito de Reprodução Interpretativa para compreendermos os processos de apropriações e ressignificações feitos pelas crianças, perante aquilo que lhes é mediado. $\mathrm{O}$ autor explica que o termo reprodução não significa que as crianças estão copiando ou internalizando o mundo do adulto, mas pelo contrário, elas estão contribuindo para a ressignificação e produção cultural, tendo participação ativa na sociedade. Já o termo interpretativa é caracterizado pelos aspectos inovadores e criativos em que as crianças imaginam e manifestam suas vontades lúdicas, transformando o meio e o adaptando-o às suas vontades. Apoiados em Pinto e Sarmento (1997), o olhar das crianças sobre as coisas

permite revelar fenômenos sociais que o olhar dos adultos deixa na penumbra ou obscurece totalmente. Assim, interpretar as representações sociais das crianças pode ser não apenas um meio de acesso à infância como categoria social, mas às próprias estruturas e dinâmicas sociais que são desocultadas no discurso das crianças (p. 25).

Portilho e Tosatto (2014), na busca por uma especificidade do trabalho pedagógico nessa etapa educacional, afirmam que é preciso superar a maneira como os professores enxergam as crianças, considerando-as apenas pela repetição, reprodução, silêncio e passividade. Nessa visão, a criança só reproduz o que é transmitido pelos adultos, elas são impossibilitadas de manifestarem as suas diferentes linguagens. Em sentido contrário, Sarmento (2013) alega que precisamos pensar no trabalho pedagógico como um momento de encontro de culturas, de apropriações, linguagens e saberes, um momento em que as crianças podem dispor de suas infâncias, sendo consultadas e envolvidas nos processos pedagógicos que serão empreendidos. Contudo Pinto e Sarmento (1997), mencionam a dificuldade que os adultos têm para perceber e considerar as diversas vozes das crianças.

Partilhamos da reflexão de Gómez-Symth (2017), na qual o brincar e a direção que a brincadeira pode tomar depende das demandas, interesses e saberes dos sujeitos que brincam. Os caminhos pelos quais as brincadeiras trilham se relacionam com os sentidos e as emoções presentes no ato de brincar, que são construídos pelas subjetividades e nas interações entre pares. Pudemos perceber a ressignificação e certa imprevisibilidade na forma como as brincadeiras com bolinhas de sabão foram vivenciadas, servindo, inclusive, como um rico instrumento para que o docente repensasse a abordagem de suas aulas com as outras turmas.

\section{Considerações Finais}

Neste artigo analisamos episódios narrados por quatro professores e professoras de Educação Física que trabalham em Centros Municipais de Educação Infantil de Vitória/ES/Brasil. Focalizamos os seus modos de compreenderem, interpretarem e valorizarem as produções culturais das crianças em suas aulas.

O olhar atento e a escuta sensível para as produções culturais das crianças foram posturas comuns aos docentes participantes da pesquisa. Por isso, tão importante quanto "dar voz" as crianças, é saber ouvilas, é estar atento às suas múltiplas formas de expressão, que se manifestam constantemente por meio de diferentes linguagens, sobretudo a corporal, nos cotidianos das instituições infantis. Para Finco e Oliveira (2011), “Apesar de toda bagagem de estereótipos, as crianças pequenas encontram espaços para a transgressão (...) com seus corpos e com suas espontaneidades, problematizam e questionam esses modelos centrados no adulto." (p. 72).

A expressão "criança como sujeito de direitos", tão propalada nos documentos pedagógicos que orientam à Educação Infantil no Brasil, nos discursos docentes e nas produções acadêmico-científicas, precisa encontrar ressonância nas práticas pedagógicas cotidianas, saindo do plano das intenções e adentrando no plano das ações. Para além dos direitos clássicos, como os civis, sociais e políticos, que nem sempre são diretamente aplicáveis as crianças, outras categorias de direitos são necessárias para o reconhecimento dos infantis 
como seres ontológicos plenos e não como seres em devir. Dentre essas categorias, ressaltamos o "direito cognitivo" (Sarmento, 2013), ou seja, o direito de a criança ser levada à sério naquilo que fala, na forma como pensa e age. Consideramos as crianças como capazes de pensar e agir sobre si mesmas e não como meros receptáculos passivos da socialização imposta pelos adultos.

O reconhecimento das produções culturais das crianças exige dos adultos mediações pedagógicas intencionais, conscientes e planejadas. No caso específico desta pesquisa, a ampliação das relações dialógicas com as crianças, os arranjos de materiais e a valorização de suas reproduções interpretativas foram meios encontrados pelos professores para dar visibilidade as produçóes culturais das crianças e para reorientar as suas ações pedagógicas, considerando a centralidade dos infantis nesse processo. Dessa forma, fomentar o protagonismo, a autoria e a autonomia das crianças não eximem o professor(a) de exercer a sua docência. Não defendemos que, sob o pretexto de considerar os interesses e necessidades das crianças, as aulas caiam em um espontaneísmo, em um laissez-faire, mas apostamos em uma escola infantil que, ao cumprir a sua função social, não anule a criança como sujeito ativo de sua socialização e do seu desenvolvimento.

As produções curriculares de crianças e professores, construídas nos cotidianos dos CMEI de Vitória/ES, se contrapõem radicalmente a lógica de escolarização da Educação Infantil em curso no país. Recentemente o Governo Federal lançou uma consulta, endereçada às escolas de Educação Infantil do Brasil, sobre a pertinência da adoção do livro didático e de apoio ao professor nessa primeira etapa da Educação Básica. O Programa Nacional do Livro Didático (PNLD), apoiado na prescrição curricular da Base Nacional Curricular Comum, pretende unificar os currículos de Educação Infantil no país, viabilizando, dessa forma, que as avaliações em larga escala sejam aplicadas nessa etapa. É uma forma de controle que anula a autonomia dos professores e a autoria das crianças, sob a égide de um currículo externamente orientado que desconsidera as culturas locais e as crianças como sujeitos históricos, socialmente situadas. Estabelece-se, dessa forma, uma precarização da atividade docente, separando quem pensa o currículo de quem o aplica.

Sem aprofundarmos nos interesses comerciais das editoras que estão subjacentes ao livro didático, do ponto de vista epistemológico, teórico, didático-pedagógico e curricular a adoção desse material é incompatível com uma concepção de infância que considera a criança como protagonista, autora de suas práticas, produtora de cultura e "sujeito de direitos". Em vez de campos de experiência, com a unificação curricular preconizada pelo livro didático, teremos campos de experimentação, com a aplicação de currículos pré-estabelecidos por agentes externos. Por isso, dar visibilidade às produções curriculares de professores e crianças é uma forma de resistir, uma necessidade de reconhecer experiências teóricas e práticas acumuladas pelas redes de ensino e pelo campo acadêmico-científico, que foram desconsideradas na imposição desse modelo de escolarização da Educação Infantil em curso no Brasil.

\section{REFERÊNCIAS}

Barbosa, I. G. (2002). Educação infantil: o lugar da pedagogia e da educação física em uma perspectiva sócio-históricodialética, Pensar a Prática, 5, 71-91.

Bellotti, S. (2019). Propuestas de Enseñanza de la Educación Física en el Nivel Inicial. Buenos Aires: $13^{\circ}$ Congreso Argentino y $8^{\circ}$ Latinoamericano de Educación Física y Ciencias. Universidad Nacional de La Plata.

Brasil. (2009). Resolução CNE/CEB n 05/2009 de 17 de dezembro de 2009. Institui as Diretrizes Curriculares Nacionais para a Educação Infantil. Recuperada de http://portal.mec.gov.br/index.php?option=com docman \&view=download\&alias=2298-rceb005-09\&category slug=dezembro-2009-pdf\&Itemid=30192 .

Brasil. (2013). Diretrizes curriculares nacionais para a educação infantil. Brasília: MEC, SEB.

Borba, F. S. (2002). Dicionário de usos do Português do Brasil. São Paulo: Ática.

Certeau, M. (1994). A invenção do cotidiano: artes de fazer ( $8^{\mathrm{a}}$ ed.). Petrópolis: Vozes.

Corsaro, W. (2005). Entrada no campo, aceitação e natureza da participação nos estudos etnográficos com crianças pequenas. Revista Educação \& Sociedade, 26(91), 443- 464. 
Corsaro, W. (2009). Reprodução interpretativa e cultura de pares. In F. Muller \& A. M. A. Carvalho (Orgs.), Teoria e prática na pesquisa com crianças: diálogos com William Corsaro (pp. 31-50). São Paulo: Cortez.

Cunha, N. H. S. (2010). Brinquedoteca: um mergulho no brincar ( $4^{a}$ ed.). São Paulo: Aquariana.

Dahlberg, G.; Pense, A., \& Moss, P. (2003). Qualidade na educação da primeira infância: perspectivas pós-modernas. Porto Alegre: ARTMED.

Dupuy, M. (2019). Prácticas pedagógicas críticas en Educación Física: un examen de la actuación. $13^{\circ}$ Congreso Argentino y $8^{\circ}$ Latinoamericano de Educación Física y Ciencias. La Plata. Buenos AIres: Universidad Nacional de La Plata.

Ferrara, L. D. (2003). Epistemologia da comunicação: além do sujeito e aquém do objeto. São Paulo: Loyola.

Finco, D., \& Oliveira, F. (2011). A sociologia da pequena infância e a diversidade de gênero e de raça nas instituiçóes de educação infantil. In A. L. G. Faria \& D. Finco (Orgs.), Sociologia da infância no Brasil (pp. 55-80). Campinas: Autores Associados.

Gómez-Smyth, L., \& Capllonch-Bujosa, M. (2015). Intervenciones docentes para la construcción de situaciones lúdicas en clases de Educación Física Infantil. EFEI, 4(4), 37-46.

Gómez Smyth, L. (2017). La construcción de instancias de juego con rasgos lúdicos en la educación física del nivel inicial. Sportis Sci J, 3(3), 569-588.

Gómez-Smyth, L. (2019). Prácticas pedagógicas en la enseñanza de la Educación Física del Nivel Inicial. $13^{\circ}$ Congreso Argentino y $8^{\circ}$ Latinoamericano de Educación Física y Ciencias. Buenos Aires: Universidad Nacional de la Plata.

Horn, M. G. S. (2004). Sabores, cores, sons, aromas. a organização dos espaços na Educação Infantil. Porto Alegre: Artmed.

Jobim e Souza, S., \& Castro, L. R. (2008). Pesquisando com crianças: subjetividade infantil, dialogismo e gênero discursivo. In S. H. V. Cruz (Orgs.), A criança que fala: a escuta de crianças em pesquisas (pp. 52-78). Cortez Editora: São Paulo.

Martins, R. L. R., Santos, W., Mello, A. S., \& Votre, S. J. (2016). Protagonismo infantil na educação física: Uma experiência pedagógica com a capoeira. Revista Portuguesa de Educação, 29(2), 59-79.

Mello, A. S., Santos, W., Klippel, M. V., Rosa, A. P., \& Votre, S. J. (2014). Educação física na educação infantil: produção de saberes no cotidiano escolar. Revista Brasileira de Ciência do Esporte, 36(2),467-484.

Mello, A. S., Zandomínegue, B. A. C., Vieira, A. O., Silva, A. C., Assis, L. C., Barbosa, R. F. M., \& Martins, R. L. R. (2015). Pesquisa com crianças na Educação Infantil: diálogos interdisciplinares para produção de conhecimentos. Motrivivência, 27, 1-16.

Neira, M. G. (2008). Educação física na educação infantil: algumas considerações para a elaboração de um currículo coerente com a escola democrática. In O. Schneider \& N. A. Figueiredo Filho (Orgs.), Educação física para a educação infantil: conhecimento e especificidade (pp. 45-95). São Cristóvão/SE: Editora UFS.

Pedrosa, M. I., \& Carvalho, A. M. A. (2005). Análise qualitativa de episódios de interação: uma reflexão sobre procedimentos e formas de uso. Psicologia: Reflexão e crítica, 18(3), 431-442.

Pinto, M., \& Sarmento, M. J. (1997). As crianças e a infância: definindo conceitos, delimitando o campo. In M. Pinto \& M. J. Sarmento (Orgs.), As crianças, contexto e identidades (pp. 9-30). Braga: Universidade do Minho.

Portilho, E. M. L., \& Tosatto, C. C. (2014). A criança e o brincar como experiência de cultura. Revista Diálogo \& Educação, 14, 737-758.

Rezende, D. O. (2012). O brincar livre de crianças da brinquedoteca: análise da frequência de ações motoras, tipos de brinquedos, brincadeiras e interaçôes sociais (Dissertação de Mestrado em Educação Física). Recuperada de http: //www.teses.usp.br/teses/disponiveis/39/39133/tde-18052012-151519/pt-br.php.

Richter, A. C., \& Vaz, A. F. (2005). Corpos, saberes e infância: um inventário para estudos sobre a educação do corpo em ambientes educacionais de 0 a 6 anos. Revista Brasileira de Ciências do Esporte, 26(3), 73-83.

Santos, A. O., Silva, A. L., Melo, A. P. S., Santos, M. A., \& Fonseca, E. S. (2011). Reaproveitamento de materiais recicláveis na construção de brinquedos na Educação Infantil. Anais do Simpósio Internacional de Ciências 
Integradas da Unaerp, Guarujá/SP. Recuperado de https://www.unaerp.br/documentos/1249-reaproveitame nto-de-materiais-reciclaveis-na-construcao-de-brinquedos-na-educacao-infantil/file .

Sarmento, M. J. (2013) A sociologia da infância e a sociedade contemporânea: desafios conceituais e praxeológicos. In R. T. ENS \& M. C. Garanhani (Orgs.), Sociologia da Infância e a formação de professores (pp.13-46). Curitiba: Champagnat.

Sarmento, M. J. (2005). Gerações e alteridade: Interrogações a partir da sociologia da infância. Educação \& Sociedade, 26(91), 361-378.

Souza, E. C. (2006). Autobiografias, histórias de vida e formação: pesquisa e ensino. Porto Alegre: EDPUCRS; Salvador: EDUNEB.

Souza, E. C. (2008). Memoriais autobiográficos, profissionalização docente e identidade: histórias de vida e formação na pós-graduação. In M. C. Passeggi, \& T. M. Barbosa (Orgs.), Memórias ememoriais:pesquisa e formação docente (pp. 119-134). Natal: EDUFRN; São Paulo: PAULUS.

Tomás, C. (2017). Para além de uma visão dominante sobre as crianças pequenas: gramáticas críticas na educação de infância. Revista Humanidades \& Inovação, 4(1), 13-20.

Varotto, M. A., \& Silva, M. R. (2004). Brinquedo e indústria cultural: Sentidos e significados atribuídos pelas crianças. Motrivivência, 23, 169-190.

\section{Notas}

1 Esta pesquisa foi aprovada pelo Comitê de Ética em Pesquisas com Seres Humanos, da Universidade Federal do Espírito Santo (Protocolo ${ }^{0} 2.182 .093 / 2017$ ).

2 O Pibid é um programa de aperfeiçoamento da formação de professores para atuar na educação básica. Concede bolsas a alunos de licenciatura participantes de Projetos de Iniciação à Docência desenvolvidos por Instituições de Educação Superior (IES) em parceria com escolas de educação básica da rede pública de ensino. As parcerias promovem a inserção dos estudantes no contexto das escolas públicas desde o início da sua formação acadêmica para que desenvolvam atividades didático-pedagógicas, sob orientação de um professor coordenador do curso e de um professor da escola.

3 Para Certeau (1994), as ações táticas são calculadas e determinadas pela ausência de um lugar próprio. São formas astuciosas de subverter a ordem imposta.

4 Recuperado de https://www.ivancruz.com.br/galeria?lightbox=dataItem-itav8x2h1. (27 de julho de 2018).

\section{BY-NC-SA}

